\title{
O letramento acadêmico em inglês: dificuldades na confecção da seção introdução de artigos acadêmicos
}

\section{English academic literacy: difficulties in writing the introduction section of research articles}

\author{
Marília Mendes Ferreira* \\ Universidade de São Paulo - USP \\ São Paulo - São Paulo/Brasil
}

RESUMO: Este trabalho discute as dificuldades de um pós-graduando da área de energia na confecção da introdução de um artigo acadêmico em inglês. Duas versões do texto foram analisadas (uma após a instrução e outra após a conferência com a instrutora), comparando-as com os modelos de introdução de Swales (2004) e de Samraj (2002) ensinados no curso. O aluno apresentou os seguintes problemas: a narração como modo de organização retórica do texto, a ausência do movimento 2 dos modelos, uma escolha inadequada de léxico. A combinação desses elementos impediu que o texto apresentasse o valor cultural do gênero textual artigo acadêmico - a autopromoção. Os dados suscitam questionamentos sobre os limites da descrição empírica dos gêneros textuais e de seu ensino.

PALAVRAS-CHAVE: artigo acadêmico, introdução, energia, ensino baseado em gêneros textuais.

ABSTRACT: This paper discusses the difficulties of a graduate student in the area of Energy in writing the introduction of a research paper in English. Two versions of the text (one after the instruction and another after the conference with the instructor) were compared with Swales' (2004) and Samraj' (2002) models of introductions taught in the English academic writing course offered. The student revealed the following problems: narration as the rhetorical mode of organization of the text, the absence of Move 2 of the introduction, inappropriate choice of vocabulary. The combination of these factors prevented the article from having the cultural value of the academic article genre: self-promotion. The data raise questions about the limits of empirical description of genres and their teaching based on this kind of description.

KEYWORDS: research article, introduction, energy, genre-based writing instruction.

*mmferreira@usp.br; ferreira363@yahoo.com 


\section{Introdução}

$\mathrm{Na}$ economia do conhecimento, a escrita, juntamente com o conceito maior de letramento, adquire um papel fundamental e, portanto, um alto valor agregado (BRANDT, 2005; JUSWICK et al., 2006; WARSCHAUER, 2000). Warschauer (2000), em um texto sobre o futuro do ensino de inglês como língua estrangeira às portas do terceiro milênio, chama a atenção para a importância da habilidade escrita nessa língua em diversos contextos e para a interação crescente com o advento da internet, que permitiria uma maior colaboração e solução de problemas.

No mundo acadêmico, o inglês é considerado a língua franca das ciências (FLOWERDEW; PEACOCK, 2001; GIBBS, 1995; WOOD, 2001). Os motivos remontam ao poderio econômico e político dos Estados Unidos - que apenas recentemente tem sido ameaçado - e à própria atividade científica, que alimenta esse status do inglês. O fator de impacto, que foi criado como uma medida de qualidade para a publicação acadêmica, prescreve que as revistas e os artigos tenham um alto número de citaçôes, e, para que tal ocorra, faz-se necessário atingir visibilidade por meio da utilização do inglês (WOOD, 2001). Além disso, o uso do inglês permite o aumento da rede de relaçôes entre os acadêmicos (networking) (WOOD, 2001), considerado um dos fatores fundamentais para a inserção internacional de pesquisadores de regiôes periféricas (LILLIS; CURRY, 2010).

No Brasil, a política grandemente incentivada pela CAPES de publicação internacional leva à instauração de uma necessidade do letramento acadêmico por parte dos pesquisadores e pós-graduandos e na consequente conversão desse tipo de letramento em uma commodity. ${ }^{1}$ Essa necessidade social impõe a necessidade de pesquisas sobre o modo como os brasileiros estão lidando com esse letramento.

O presente artigo vai nessa direção. Ele se organiza da seguinte forma: Primeiramente, será feita uma breve revisão da literatura sobre o letramento acadêmico $^{2}$ no exterior e no Brasil. Depois, a metodologia do estudo será

\footnotetext{
${ }^{1}$ O artigo "Escolinha de cientistas" (Folha de S. Paulo, 30 out 2011, Caderno 11) ilustra o atual valor cultural do letramento acadêmico em inglês no Brasil.

${ }^{2}$ Neste artigo, o termo letramento acadêmico se refere genericamente à leitura e à escrita de gêneros acadêmicos. Não se deve confundir com a tradução de uma linha de estudos baseada nos Novos Letramentos denominada Academic Literacies, ou Letramentos Acadêmicos, representada por Jones, Turner e Street (1999) e Lillis e Curry (2010), por exemplo.
} 
descrita, seguida dos resultados e sua discussão. $\mathrm{O}$ artigo é concluído com algumas reflexões sobre as limitações dos estudos de gênero textual e de seu ensino com foco no empirismo.

\section{Os estudos sobre a escrita acadêmica em inglês no exterior e no Brasil}

A escrita acadêmica, que faz parte do letramento acadêmico, tem sido abordada por diferentes perspectivas. $\mathrm{O}$ aspecto estrutural/composicional de gêneros textuais acadêmicos como apresentaçôes acadêmicas, abstracts e artigos acadêmicos tem sido investigado, mais extensivamente, pela escola de gênero textual EAP (English for Academic Purposes) ${ }^{3}$ (SWALES, 1990, 2004; SWALES; FEAK, 2000, 2004). Essa escola objetiva identificar os passos obrigatórios e opcionais que compõem os movimentos, que, por sua vez, constituem os gêneros textuais. Esses movimentos fazem com que o gênero alcance seu objetivo social e seu propósito comunicativo (ASKAHAVE; SWALES, 2001; SWALES, 1990). ${ }^{4}$

Outro aspecto abordado são as estruturas linguísticas que caracterizam o discurso ${ }^{5}$ acadêmico. Hyland, grande representante da descrição desse tipo de discurso pela metodologia da Linguística de Corpus, vem estudando vários itens, como o uso de imperativos (HYLAND, 2002), de expressões formulaicas (2008) e do metadiscurso (2004).

Em relação aos aspectos sociais, a escola de gêneros textuais da Nova Retórica se preocupa em investigar, pela etnografia, como o contexto em que se insere o gênero acadêmico influencia a confecção do texto (BAZERMAN, 1988), enquanto os Novos Letramentos abordam também os aspectos sócioeconômico-institucionais por essa metodologia (LILLIS; CURRY, 2010). Fora do campo dos estudos linguísticos, a sociologia da ciência explora o processo da confecção do texto acadêmico e o jogo de interesses e de forças envolvidos oriundos de diversos papéis sociais, como os de pareceristas, editores e orientadores (KNORR-CETINA, 1981; LATOUR; WOOLGAR, 1979).

\footnotetext{
${ }^{3}$ Inglês para fins acadêmicos.

${ }^{4}$ Apesar de Askahave e Swales (2001) buscarem desenvolver a noção de propósito comunicativo que centraliza a definição de gênero textual de Swales (1990), o conceito de propósito ou objetivo ainda constitui um elemento embasador do conceito de gênero textual na perspectiva EAP.

${ }^{5}$ Discurso está sendo utilizado aqui como língua em uso.
} 
A cienciometria ${ }^{6}$ se detém no aspecto quantitativo da atividade científica, buscando identificar relaçóes significativas estatisticamente entre variáveis preestabelecidas. Essas informaçōes alimentam dados estatísticos sobre a produção científica de áreas disciplinares e seu fator de impacto (MENEGHINI; MUGNANI; PACKER, 2006; PACKER; MENEGHINI, 2006); a relação entre proficiência em inglês de pesquisadores e sua produção internacional (VASCONCELOS; SORENSON; LETA, 2007); e a relação entre proficiência em inglês, publicação e investimentos na pesquisa (MAN et al., 2004), para citar alguns exemplos. Esses estudos são de caráter conformista, por ignorarem questôes geopolíticas envolvidas na publicação e nos próprios conceitos com os quais trabalham como o fator de impacto, por exemplo.

Há estudos que se detém na escrita do aluno e no seu processo de aprendizagem. Alguns aspectos dessa relação conflituosa da socialização do aluno estrangeiro com o discurso acadêmico em inglês são o plágio (FERREIRA; SANTOS, 2011; PECORARI, 2001, 2003); a identidade do escritor (IVANIC, 1998); as dificuldades linguísticas frente ao padrão do nativo (CHARLES, PECORARI; HUNSTON, 2009); a relação do aluno com a abordagem pedagógica (CASANAVE, 1995; JOHNS, 2001); as dificuldades em decorrência de diferenças culturais (DUSZAK, 1997; CONNOR; NAGELHOUT; ROZYCKI, 2008; CONNOR, 2011); as estratégias do aluno para subverter a imposição do modelo retórico anglo-saxão (CANAGARAJAH, 1996, 2002); e o contexto institucional, e consequentemente político e econômico, que envolve o ensino da escrita acadêmica (JONES, TURNER; STREET, 1999; LILLIS, 2001).

Os estudos que focam no contexto de uso do discurso acadêmico pelos alunos estrangeiros - onde as situações de conflito emergem de forma mais contundente - e na escrita desses alunos são comumente críticos. Eles advogam por pedagogias e/ou posicionamentos críticos em relação à imposição da retórica anglo-saxã, geralmente estadunidense, à escrita acadêmica.

A perspectiva dos Novos Letramentos (JONES, TURNER; STREET, 1999; STREET, 2001, LILLIS; CURRY, 2010) e a abordagem geopolítica de Canagarajah (2002) se inserem nessa visão na medida em que questionam a prática discursiva monocultural da academia e defendem a abertura para a

\footnotetext{
${ }^{6}$ A cienciometria é o tratamento estatístico de informações de diversos aspectos da atividade científica com o objetivo de informar políticas na área. É um ramo da sociologia da ciência (MACIAS-CHAPULA, 1998).
} 
negociação dessas práticas. Em especial, Canagarajah (2002), por ser de um país periférico, Sri Lanka, explora aspectos pouco abordados nos estudos sobre o letramento acadêmico em inglês, como as relaçôes entre países do centro e da periferia (denominação utilizada por ele) e sua influência nas políticas de publicação em periódicos internacionais, nas práticas de publicação das universidades dessas regiōes e nas práticas textuais que refletem culturas diferentes.

No campo da investigação pedagógica, a literatura vem clamando por mais estudos que investiguem o impacto da pedagogia baseada em gêneros textuais ou em técnicas advindas dos estudos descritivos no letramento acadêmico do aluno em inglês (CHENG, 2006; TARDY, 2006).

Concernente às recomendaçôes pedagógicas para o ensino da escrita acadêmica, há duas correntes: a generalista, que propõe cursos de redação acadêmica de cunho geral, para alunos de diversas áreas do conhecimento (SWALES; FEAK, 2000, 2004, por exemplo), e a especialista, que defende cursos específicos para cada área do conhecimento, já que cada comunidade discursiva possui suas regras do discurso acadêmico (HYLAND, 2002). A generalista possui bastante aceitação no mercado editorial e auxilia no estabelecimento da retórica americana como padrão na escrita científica (SWALES; FEAK, 2000; 2004).

Há propostas que promovem a socialização do discurso acadêmico por meio da investigação etnográfica dos gêneros textuais utilizados pela comunidade discursiva. Os alunos aprendem a escrever de acordo com as normas da sua comunidade discursiva não num curso de escrita acadêmica geral, mas cursando as disciplinas que compōem a grade curricular do seu curso. Os programas dessas disciplinas são elaborados de modo a contemplar as práticas escritas, os gêneros textuais da comunidade discursiva, e não somente o conteúdo a ser transmitido. Essa abordagem pode ou não apresentar caráter crítico (CASANAVE, 1995; JOHNS, 1997). Já Canagarajah (2002) sugere atividades de ensino mais questionadoras do status quo da atividade de publicação comandada pelo primeiro mundo e empoderadoras para o aluno estrangeiro.

No Brasil, a pesquisa sobre o ensino da escrita em inglês ainda é escassa - o que reflete o desprestígio dessa habilidade no ensino de inglês em geral, comparado à oralidade e à leitura, por exemplo (FERREIRA, 2011; PENNYCOOK, 1994; SOUZA, 2002). Os estudos já abordaram os seguintes temas: feedback (DELLAGNELO, 1998; FIGUEIREDO, 2001), o processo de ensino-aprendizagem na área de educação a distância (FREIRE, 
2000; GARCIA, 2004), os erros cometidos pelos alunos (KHUWAILEH, 2001; FIGUEIREDO, 2005), o uso da análise sistêmica como base para a produção de textos (BERALDI; FONTES, 2004), a análise do contexto de produção de textos e de sua organização textual (ZYGMANTAS, 2006), a busca de diferentes estratégias de reescritura para melhora da produção textual (DELLAGNELO; TOMITCH, 1999), o processo de escrita do aluno e suas crenças em relação à escrita em inglês (LAIA, 2008) e o ensino da escrita em escola de idiomas (SOUZA, 2002). Garcia (2004) coletou seus dados em uma escola de idiomas; Laia (2008), num centro de línguas para a escola pública (CIL), e os demais coletaram seus dados em ambiente universitário. Portanto, não há um quadro geral da situação do ensino da escrita em inglês no Brasil nos diversos contextos institucionais.

A história do letramento acadêmico em inglês no Brasil enfatizou a leitura, e não a escrita, com a implementação do Projeto Inglês Instrumental da PUC-SP na década de 1980. Esse projeto contribuiu muito para o desenvolvimento da área através da sensibilização da academia brasileira para essa necessidade, da valorização da leitura e da introdução de técnicas para seu ensino e prática. Por outro lado, com a atual pressão de agências do governo e das universidades sobre o pesquisador brasileiro para publicar em inglês, as necessidades em relação ao inglês para fins específicos se alteram drasticamente: não somente ler a pesquisa produzida no exterior, mas, principalmente, divulgar a sua própria num ambiente cada vez mais competitivo e regido por regras pouco claras (STREET, 1998).

Diante desse quadro, mais pesquisas são necessárias, seja de base (de retórica intercultural que contraste o português e o inglês, de pesquisas sobre os textos acadêmicos em inglês escritos por brasileiros), seja do ensinoaprendizagem desse discurso (impacto dos cursos dados na escrita do aluno, investigação das dificuldades dos alunos com o discurso acadêmico em inglês e nos diferentes gêneros dessa atividade).

Para ilustrar essa escassez, destaco aqui o número especial da Revista Brasileira de Linguistica Aplicada de 2011 (Belo Horizonte, v. 11, n. 4) sobre ensino de línguas para fins específicos e da revista Linguagem em (Dis)curso de 2006 (Tubarão, v. 6, n. 3) sobre gêneros textuais ensino-aprendizagem. No primeiro, de seis artigos relacionados ao inglês, somente um tratava do ensino da escrita nessa língua (DAMIÃO, 2011), enquanto dois se referiam à leitura (BEATO-CANATO, 2011; DIAS, 2011). O estudo de Damião (2011) também contemplava a leitura. No segundo, apesar de ser um número especial 
contemplando tanto o português quanto línguas estrangeiras, não houve nenhum artigo com foco no ensino da escrita acadêmica em inglês, e somente um estudo contrastivo (português-inglês) (ARAÚJO, 2006).

Em outros periódicos, encontraram-se mais dois estudos. Castro (2005) descreve um curso de redação acadêmica para graduandos de caráter generalista e com foco em técnicas colaborativas. Guiraldelo e Damião (2007) reportam as dificuldades de alunos de graduação em engenharia em escrever abstracts em inglês. Ferreira (2011) analisa as concepçôes de escrita e de ensino de uma série de livros didáticos importados para o ensino de inglês. Dos poucos estudos sobre ensino, alguns se limitam a descrever a experiência didática (CASTRO, 2005; DAMIÂO, 2011; GUIRALDELLO; DAMIÃO, 2007).

Como se pode observar, a escrita acadêmica em inglês constitui uma área de investigação multifacetada e que necessita de maiores investigaçōes no Brasil. Este trabalho objetiva exatamente analisar as dificuldades de pósgraduandos em energia de uma universidade pública brasileira por meio dos artigos acadêmicos em inglês produzidos por eles para publicação. Dessa forma, espera-se contribuir para as pesquisas na área no Brasil.

\section{Metodologia}

\section{0 curso}

O curso ministrado aos alunos teve duração de 15 semanas, perfazendo um total de 45 horas, e composto de três unidades: resumo, ${ }^{7}$ artigo acadêmico e abstract. ${ }^{8}$ Ele foi elaborado a partir de três perspectivas teóricas. O EAP foi utilizado para a análise de gêneros acadêmicos (capítulos dos livros Academic Writing for Graduate Students e English in Today's Research World foram utilizados) e para o ensino de expressões formulaicas, '9 frequentemente usadas na área (HARWOOD, 2005; HYLAND, 2008). O componente geopolítico foi inspirado em Canagarajah (2002). Atividades foram aplicadas com o objetivo de promover nos alunos a consciência retórica tanto da organização do gênero quanto das estruturas linguísticas mais utilizadas pela área de energia.

\footnotetext{
${ }^{7}$ Resumo, aqui, é considerado um gênero escolar (JOHNS, 1997).

${ }^{8}$ Esses três gêneros foram escolhidos com base em uma averiguação feita com a comunidade do instituto onde foi oferecido o curso.

${ }^{9}$ Lexical bundles, em inglês.
} 
Os alunos escreveram nos três gêneros ensinados em duas versões. A primeira foi corrigida e discutida em encontro individual com o instrutor e, posteriormente, reescrita para ser avaliada com nota.

$\mathrm{O}$ instrutor do curso era um professor de inglês proficiente e experiente, orientando de mestrado da autora deste artigo e preparado por esta para ministrar o curso. A ele coube ministrar a maioria das aulas, corrigir as versões preliminares e finais dos textos e corrigir tarefas. Já à coordenadora e criadora do curso coube a elaboração dos planos de aula, a escolha dos textos, a supervisão da correção do instrutor, o oferecimento das conferências, a correção das versões preliminares e finais dos textos e o oferecimento das aulas sobre a história do artigo acadêmico e sobre o letramento crítico.

As conferências não foram realizadas pelo instrutor pela sua inexperiência com essa prática e por se tratar do momento da coleta de dados da pesquisa.

\section{Os participantes}

Os alunos foram selecionados de acordo com o nível de proficiência, através de testes oral e escrito segundo as escalas de correção do First Certificate in English (FCE). O teste oral, que foi feito pela autora deste artigo e coordenadora do curso e foi observado por um terceiro, objetivou averiguar se o curso poderia ser ministrado em inglês, o que se confirmou. $\mathrm{O}$ teste escrito, por sua vez, foi corrigido por três avaliadores: a coordenadora do curso, o ministrante do curso e uma assistente de pesquisa. A função da prova escrita foi analisar se os alunos possuíam nível suficiente para a escrita com foco na publicação em inglês.

Seis alunos (quatro mestrandos e dois doutorandos) participaram do curso, sendo duas mulheres e quatro homens, com média de idade de 34,5 anos.

\section{A coleta de dados}

Os alunos entregaram no início do curso um texto de sua autoria ou coautoria em inglês acompanhado de uma ficha que fornecia informações sobre a origem do tema da pesquisa, ${ }^{10}$ os autores e uma legenda para identificação das partes que o aluno havia escrito. ${ }^{11}$ Esses artigos foram elaborados a partir de suas

\footnotetext{
10 Ver Anexo A.

${ }^{11}$ A coautoria teve de ser considerada aqui, já que ela faz parte das práticas textuais da área da energia.
} 
próprias pesquisas de doutorado ou mestrado. Ao fim da unidade sobre o artigo acadêmico, a versão do texto entregue no início do curso foi reformulada pelos alunos, submetida para correção e discutida em conferência - um encontro presencial com a coordenadora do curso para discutir a correção da versão preliminar do texto. Após essa conferência, o texto foi novamente corrigido e submetido na sua versão final. No presente artigo, as dificuldades dos alunos com o letramento acadêmico em inglês serão discutidas a partir das introduções do mestrando $\mathrm{G}$ em suas versōes preliminar e final.

\section{A metodologia de análise dos dados}

Os artigos dos alunos foram analisados segundo o modelo IMRD ${ }^{12} \mathrm{de}$ Swales (2004) e o modelo de introdução de Samraj (2002), aplicável para artigos empíricos. Esse conteúdo foi ensinado aos alunos durante o curso e utilizado como critério de avaliação da sua aprendizagem do gênero.

O processo de conscientização retórica dos alunos foi efetuado através da verificação da aplicabilidade desses modelos aos textos publicados nos periódicos mais importantes e escolhidos por eles próprios. Foi sugerido, inclusive, que eles trouxessem textos da bibliografia de suas pesquisas. Concluiu-se que o modelo IMRD descreve os artigos da área, apesar do seu caráter interdisciplinar, que congrega campos do conhecimento diversos como direito, sociologia, engenharia elétrica e ciências da computação.

Algumas peculiaridades foram destacadas por nossa análise e pelos alunos através das observações dos textos da área, como o uso de informação prévia (presenting background information) em diferentes movimentos e uma valorização dos passos de contextualização do tema (claiming centrality) e da identificação de lacunas de pesquisa (indicating a gap) no mundo (SAMRAJ, 2002). A área de energia parece conferir mais destaque à lacuna advinda do mundo do que à lacuna oriunda da pesquisa prévia. Essa preocupação da área em destacar a importância social da pesquisa a ser reportada foi comprovada em análise de artigos publicados em periódicos importantes da área. ${ }^{13}$

\footnotetext{
${ }^{12}$ Introduction (Introdução), Methods (Metodologia), Results (Resultados) e Discussion (Discussão). Ver, no Anexo A, os modelos de introdução de Samraj (2002) e Swales (2004).

${ }^{13}$ Solera (2011) chega a esse resultado através de sua análise de introduções de 15 artigos da área de energia, comparando-os com o modelo de introdução de Swales (1990, 2004) e Samraj (2002).
} 


\section{A análise dos dados}

As correções da versão preliminar providas pela autora e coordenadora do curso foram de caráter direto (o texto do aluno foi corrigido explicitamente) e indireto (foram feitas perguntas ao aluno para que refletisse sobre suas escolhas no texto). O primeiro tipo incidiu mais sobre aspectos gramaticais, sem conexão com a audiência, e o segundo, sobre a estrutura esquemática da introdução e sobre escolhas linguísticas que pudessem afetar a interatividade do texto.

A conferência seguiu os comentários e perguntas feitos pela coordenadora na versão preliminar. Quanto aos aspectos linguísticos, foram discutidos o uso ou não da primeira pessoa pela área e o uso do tempo verbal; em relação à estrutura esquemática, foram discutidas a falta de explicitação da lacuna a ser preenchida pela pesquisa do aluno e a contribuição do seu estudo para a área e de uma sentença contendo o objetivo do estudo. Enfatizou-se também que a narração não é utilizada no gênero textual artigo acadêmico.

Comparando as duas versóes entre si e elas com o modelo de introdução adotado, detectam-se poucas alteraçôes. As duas versōes seguem a seguinte estrutura esquemática: movimento 1 (passo $1 \rightarrow$ passo 2 ), movimento 3 (passo $2 \rightarrow$ passo 6). ${ }^{14}$ Por essa sequência, pode-se notar que o aluno não realizou o movimento 2 do modelo (estabelecendo o nicho) em nenhuma das duas versões apresentadas. Uma das razões para essa ausência foi a estrutura narrativa adotada pelo aluno para organizar o artigo acadêmico. Outro problema apresentado foram as escolhas lexicais inadequadas. Como resultado, o texto não apresenta um tom promocional de competitividade que caracteriza o artigo acadêmico (BERKENKOTTER; HUCKINS, 1995). Por outro lado, $G$ foi capaz de eliminar as marcas de primeira pessoa da versão preliminar. Nas aulas, os alunos comentaram que a área não aceita o uso desse pronome.

Pelo fato de o movimento 2 ser um elemento fundamental para a promoção da pesquisa, já que é por ele que o autor, explicitamente, mostra a relevância do tema, esse movimento foi escolhido como unidade de análise dos dados.

\footnotetext{
${ }^{14}$ Movimento 1 - estabelecendo o território; passo 1: fazer generalizações sobre o tópico com nível crescente de especificação (SWALES, 2004); passo 2: apresentar informações prévias (SAMRAJ, 2002).

Movimento 3 - passo 2: ocupando o nicho, apresentar as perguntas de pesquisa ou hipóteses (opcional) (SWALES, 2004); passo 6 (mais provável em algumas áreas que em outras): afirmar o valor da pesquisa (SWALES, 2004).
} 


\section{O movimento 2 (estabelecendo o nicho)}

A maior parte da introduçāo, em ambas as versōes, é utilizada para fornecer informaçōes prévias, necessárias para a compreensão do artigo (presenting background information). A contextualização do tema (movimento 1) é realizada através de referências aos problemas do mundo, e não de pesquisas da área (claiming centrality in real world) (SAMRAJ, 2002).

Initially, in the Research and Development (R\&D) programs promoted by National Electrical Energy Agency (ANEEL, Brazilian regulator on electricity market), there were a large number of research initiatives motivated by the spirit of technological innovation. In the last years there have been corrections for the main objectives of these programs towards a more practical and applicable approach of the methods and ideas generated for the utilities of the electrical sector. [início do texto]

O uso extenso desse tipo de informação possui dupla função: 1) apresentar informação necessária para compreender o artigo, a pesquisa a ser reportada prática comum na área de energia; e 2) uma ação retórica argumentativa para mostrar o valor do tema e, assim, justificar o movimento seguinte (ocupando o nicho) no mundo em vez de nas pesquisas já realizadas. Portanto, o extenso uso do passo 2 funcionaria como um movimento de estabelecimento do nicho, ou seja, o movimento 2. Faz-se relevante notar que não há nenhuma citação nessa seção do artigo.

Em termos da estrutura esquemática da introdução do artigo acadêmico, G parece ter consciência das açōes retóricas esperadas: contextualizar o tema, mostrar sua importância no mundo e dizer o que se propõe na pesquisa a ser reportada. Ele também domina práticas discursivas de sua comunidade, como a valorização da pesquisa no contexto social, reforçada pela extensa informação prévia fornecida. Essa informação consiste na explicação do processo de desenvolvimento de redes utilizadas em usinas elétricas, em particular, naquela que é objeto de seu estudo. A valorização também ocorre no movimento 3, passo 5 , ao referir-se à contribuição de sua pesquisa para uma usina elétrica, em particular, e para o programa de energia do governo, citado na introdução.

There would be gains for the utility (CEB) and then to the entire distribution sector and consumers, fulfilling the objectives proposed by the ANEEL R \& D program.

Muito provavelmente, esses valores foram adquiridos pela sua socialização com professores da pós-graduação e seu orientador. 
$\mathrm{G}$ apresenta uma inabilidade em explicitar os movimentos do modelo. As lacunas a serem preenchidas por seu estudo, que devem ser expressas no movimento 2, precisam ser inferidas pelas informaçôes que coloca como prévias. Na conferência, ele mesmo confessa: "it should be clear by now [fim da introdução]". O objetivo da pesquisa - parte do movimento 3 - também não é escrito claramente; ele foi formulado como uma hipótese com a utilização da oração concessiva.

We considered that if we could embed the functions of monitoring and control in these relay, we would increase the benefits in using or adopting this topology.

A hipótese sustentada é de que a dificuldade na realização do movimento 2 se deve à falta de um conhecimento conceitual do gênero artigo acadêmico. Apesar de o modelo de introdução ter sido ensinado, de Swales e Feak (2004, p. 243) abordarem o aspecto da competividade e de termos discutido isso em aula, G não percebeu a importância disso na escritura do artigo e para a atividade científica. Essa dificuldade foi apresentada pelos outros sujeitos da pesquisa e, por isso, precisa ter suas razóes investigadas mais ostensivamente.

Faz-se necessário esclarecer, aqui, que o curso procurou deliberadamente assemelhar-se a um curso supostamente regular de mercado, ${ }^{15}$ baseado em materiais didáticos de renome e com uma visão descritiva (ou empirista). Como parte do projeto, outro curso ensinou os mesmos gêneros com uma proposta pedagógica conceitual em que esse conceito não é limitado a uma descrição empírica de movimentos e passos, mas, sim, prioriza o seu ensino como uma manifestação de uma relação básica dialética de funcionamento da língua: a língua e o contexto social estão numa relação de mútua influência regida por

${ }^{15}$ Agradeço ao revisor anônimo por chamar a atenção para o que seja um curso regular de escrita acadêmica de mercado. Atualmente, arrisco dizer que tais cursos são praticamente inexistentes no mercado, mas, com a necessidade cada vez mais premente de pesquisadores e pós-graduandos brasileiros publicarem em inglês, esses cursos tendem a se proliferar, com forte probabilidade de seguirem manuais didáticos publicados por grandes editoras. $\mathrm{O}$ curso aqui descrito objetivou seguir um material didático de pesquisadores da área do discurso acadêmico de grande renome. Em oposição a essa situação, há a possibilidade de cursos de escrita acadêmica serem criados pelos próprios professores, com base em suas pesquisas e em propostas teóricas diversas, como a descrita brevemente aqui (a proposta conceitual). Para maiores detalhes desse curso, ver Ferreira (2011). 
conflitos e tensões (FERREIRA, 2005, 2009; FERREIRA; LANTOLF, 2008). A história e o porquê das regras descritas pela visão empírica são foco de questionamento na visão dialética. Com isso, o aluno passa a adquirir uma forma de pensar mais dialética que lhe permite relacionar fatos, dados e fenômenos aparentemente não integrados em um sistema, buscando explicações que vão além dos sentidos do empirismo (DAVYDOV, 1988a, b, c, d). ${ }^{16}$

\section{A narração}

Pelos modelos de introdução de Swales (2004) e Samraj (2002) e do artigo empírico IMRD (SWALES, 2004), pode-se inferir algumas características desse gênero e valores culturais a ele atrelados: a competitividade, a persuasão e a autopromoção. A competividade deve ser superada com uma estratégia persuasiva já ditada pela comunidade discursiva - a escolha de tipos de argumentos como a identificação de lacunas em pesquisas prévias ou a importância do estudo na sociedade - para convencer a audiência da importância do estudo. A sequência de movimentos da introdução e a seção discussão objetivam isso. A autopromoção é estimulada por todos os passos do movimento 2, tanto no modelo de Swales (2004) quanto no de Samraj (2002), e, no movimento 3, pelos passos 2 A e 2 B - no modelo de Samraj (2002) - e pelo passo 5 - no modelo de Swales (2004). Além disso, o uso de atenuadores (hedges) e intensificadores (boosters) ${ }^{17}$ ao longo do artigo também contribuem para a autopromoção. Portanto, a autopromoção constitui valor cultural, já que consiste numa estratégia importante para a sobrevivência no mundo competitivo da academia. A associação da competição acadêmica com a competição na natureza, através da seleção natural, está presente na metáfora biológica do nicho de Swales (1990) e na expressão "publicar ou perecer". Berkenkotter e Huckin (1995) afirmam que "o que se valoriza hoje não é tanto a quantidade de informação nos artigos, mas o quanto se promove essa

16 Ver Ferreira (2011) para a comparação dos dois cursos.

${ }^{17}$ Atenuadores e intensificadores são tipos de metadiscurso (HYLAND, 2005). Hyland o define como "um termo geral para as expressōes autorreflexivas que são utilizadas para negociar os sentidos interacionais no texto, auxiliando o escritor (ou falante) a expressar sua opinião e a engajar o leitor como membro de uma comunidade especifica" (the cover term for the self-reflective expressions used to negotiate interactional meanings in a text, assisting the writer [or speaker] to express a viewpoint and engage with readers as members of a particular community) ( $\mathrm{p} .37$, tradução nossa). 
informação" (p. 237, tradução nossa).$^{18}$ Nessa visão, não há espaço para narrativas, pois elas não são consideradas uma estratégia adequada pela academia para argumentar, persuadir, convencer, promover-se.

Os modelos de Swales e Samraj foram elaborados a partir de análises de textos de diversas áreas do conhecimento publicados em inglês e em editoras de primeiro mundo. Portanto, refletem os valores de um determinado lugar.

G, desconhecedor dessa visão conceitual do gênero textual artigo acadêmico, dos valores culturais que sustentam a sua descrição empírica, estruturou ambas as versões de modo narrativo. As escolhas lexicais ("initially", "with these ideas in mind", "started to plan", "the initial idea was") e o uso de advérbios e locuções adverbiais de tempo ("initially", "in the last years", "since the early30"," "in the late years", "later") expressam o surgimento do interesse do aluno pelo tema de sua pesquisa, a gênese do seu projeto e sua evolução. Contudo, os modelos utilizados e amplamente valorizados pelos materiais didáticos de ensino da escrita acadêmica em inglês (SWALES; FEAK, 2000, 2004) mostram que o artigo reporta resultados, e não o seu processo ou história de produção.

A narração, por ser extremamente contextual, vai de encontro à concepção de texto autônomo adotada pela academia (GEISLER, 1994). Estudos mostram que a linguagem utilizada no processo de pesquisa apresentase contextual, mas o relato da descoberta, através do gênero textual artigo acadêmico e veiculado pelo periódico, é desvinculado da sua condição de produção e reportado como uma verdade universal - que possui muito mais poder de mercado e valor a ser agregado.

Durante o curso, esse aluno se mostrou consciente do uso da narração no artigo acadêmico, pois me reportou que seu orientador já o havia advertido sobre isso nos seus textos em português, e ele havia sido apelidado pelos colegas com o nome de um escritor famoso.

Interpreto o caráter narrativo de seu texto como um efeito do seu letramento em língua materna. Como a narrativa era o modelo retórico mais acessível, ou o único, já que foi esse o ensinado ou o mais praticado nas aulas de português da escola, ele a utilizou para realizar diversas ações retóricas, como argumentar e persuadir.

\footnotetext{
18 "it is not so much the amount of news value that is remarkable in today's scientific journal arguments as it is the promoting of it" (p. 237).
} 


\section{Uso de expressões inadequadas}

O uso das expressôes "with these ideas in mind" e "the initial idea" (na versão preliminar) e "the initial idea" (na versão final) conferem ao texto um tom de incerteza sobre o estudo e sobre a competência do pesquisador, pois o que está em foco não é a pesquisa em si, mas a sua gênese. As escolhas provavelmente foram feitas devido à organização narrativa dada ao texto. Uma extensão desta pesquisa seria verificar como membros da comunidade discursiva brasileira e estrangeira interpretam esses trechos. ${ }^{19}$

\section{Modificações realizadas por $\mathbf{G}$}

As modificaçôes foram escassas, restringindo-se à eliminação de algumas sentenças, à inserção de outra e à correção de erros gramaticais. A ordem das ideias e dos parágrafos se manteve. O parágrafo abaixo foi eliminado: ${ }^{20}$

[These network protectors are present in the underground distribution systems since the early 1930's, brought in first hand by the Rio de Janeiro Tramway, Light and Power Company, today called Light S/A, following the latest model used in the New York city.] What is the purpose of this information? This technique have been employed in critical or high energy demand areas in major Brazilian cities due to its very high reliability. The project of these systems takes into account a reserve capacity so that the failure of one or more feeders will not cause the interruption of the power supplied to the consumers side. I am not sure why this info is needed. You claimed centrality, but no gap so far. What is the purpose of this part? Or maybe you are not using it properly to establish the gap, or claim centrality in the world.

G eliminou a primeira sentença provavelmente por não obter uma resposta clara para a minha pergunta. Na conferência, ele revelou já ter percebido que o parágrafo apresentava problemas, que ele precisava descrever algo, mas se mostrou mais disposto a cortá-lo do artigo. Essa modificação contribuiu para a melhora do texto, pois diminui o seu tom narrativo. Todavia,

\footnotetext{
${ }^{19}$ Apesar de eu não pertencer à comunidade discursiva da área de energia, acredito que o conhecimento sobre introduçóes de artigos acadêmicos na área de energia (SOLERA, 2011) e as informaçóes obtidas com os alunos durante as aulas de conscientização retórica me habilitam a fazer as interpretações aqui presentes.

${ }^{20} \mathrm{O}$ que está em itálico refere-se aos comentários da pesquisadora sobre o texto.
} 
as informações subsequentes apresentam potencial argumentativo que poderiam ser utilizadas como parte do movimento 2 . De qualquer forma, essa eliminação indica que o aluno não estava preparado para executar o que lhe foi pedido, provavelmente por deficiência linguística. Isso nos leva a pensar sobre a motivação do aluno diante da tarefa do curso. Por ser aluno de mestrado, ele não era obrigado, pelas normas do seu programa de pós-graduação, a publicar internacionalmente. Como consequência, ele poderia estar fazendo a tarefa para obter nota e um certificado.

O tom narrativo permaneceu, apesar da eliminação de algumas expressões de tempo. Isso impediu que a introdução se adequasse ao modelo de introdução de Swales. Devido à narração do processo de criação do projeto, não se pode extrair do texto qual era o problema que a pesquisa se propunha a resolver ou a discutir, quais as vantagens e desvantagens da solução proposta e a contribuição do estudo do aluno para melhorar essa situação. Em outras palavras, as mesmas informaçóes utilizadas na narração poderiam ter sido aproveitadas para objetivos persuasivos e de autopromoção dentro do esquema da introdução proposto por Swales. ${ }^{21}$

$\mathrm{O}$ aluno procurou retirar os pronomes de primeira pessoa do texto. Abaixo, estão dispostos lado a lado as duas versões e o efeito causado.

\section{TABELA 1}

Modificação textual nas versões preliminar e final

\begin{tabular}{l|l}
\hline \multicolumn{1}{c|}{ Versão preliminar } & \multicolumn{1}{c}{ Versão final } \\
\hline $\begin{array}{l}\text { We considered that if we could embed } \\
\text { the functions of monitoring and control } \\
\text { in these relay, we would increase the } \\
\text { benefits in using or adopting this } \\
\text { topology. }\end{array}$ & $\begin{array}{l}\text { It was considered that if the functions of } \\
\text { remote monitoring and control could be } \\
\text { embedded in these relays, it would make } \\
\text { this topology more attractive to investment } \\
\text { and also make it up-to-date with the } \\
\text { latest Smart Grid concepts. }\end{array}$ \\
\hline
\end{tabular}

Essas modificações apresentaram um aspecto positivo e outro negativo. $\mathrm{O}$ aspecto positivo foi que o aluno expandiu o texto, acrescentando informações que promoveram a importância do tema. Contudo, a conversão do texto para a terceira pessoa do singular (ou sujeito indeterminado, na

\footnotetext{
${ }^{21}$ Não se advoga, aqui, por esse modelo. O que se pretende é dizer que o modelo apresenta valores culturais que frequentemente são ignorados por propostas de análise e ensino de gêneros de base empírica.
} 
tradução para o português) apaga a possibilidade de interpretarmos a sentença como movimento 3 passo 2 (apresentação de uma hipótese) para inferirmos que a sentença ainda faz parte do longo passo 2 (apresentando informação prévia) do movimento 1 . O uso do passado e de um sujeito indeterminado confere essa ideia. $\mathrm{O}$ aluno, diante da sugestão da coordenadora na conferência para eliminar a primeira pessoa e o passado simples, não utiliza, por exemplo, expressões formulaicas ensinadas no curso para explicitar o objetivo do artigo (“This paper aims to...", “This paper adresses...”).

\section{Discussão}

As dificuldades apresentadas por $G$ para escrever a introdução de um artigo acadêmico suscitam algumas questões para discussão, relativas à qualidade do letramento acadêmico em línguas materna e estrangeira oferecido e ao valor cultural que o gênero textual carrega consigo.

Em relação ao primeiro aspecto, ficou evidente que $G$ utilizava a narração como um recurso retórico para executar as diversas ações linguísticas exigidas no artigo acadêmico, como encontrar o nicho e persuadir. Muito provavelmente, isso ocorreu devido a um letramento em língua materna deficiente, restrito ao ensino da norma culta (ROJO, 2009; ZANINI, 1999), ao uso de modelos textuais advindos da literatura (ROJO, 2009), à adoção de temas para o desenvolvimento da produção textual (GUEDES, 2009), ou pelo fato de a narração ser um gênero textual primário (BAKHTIN, 1992), portanto, um conceito do cotidiano (VYGOTSKY, 1987). Da mesma forma que $G$ utilizou-se da narração para cumprir essas necessidades do contexto acadêmico, outros alunos, expostos ao mesmo ensino pautado em poucos gêneros ou somente em um, podem adotar a mesma estratégia para desempenhar as necessidades retóricas que o mundo lhes exige. Isso nos revela que, hoje, o ensino de língua portuguesa caminha na direção correta ao expor os alunos a diversos tipos de gêneros textuais.

Por outro lado, o letramento em língua inglesa, tanto acadêmico quanto geral, encontra-se deficitário. Ao, propositalmente, adotar material didático elaborado por especialistas da área e não por autores de livros didáticos de carreira, o curso focou na descrição da fórmula do artigo acadêmico em vez de no porquê dessa descrição (comportamento tipicamente empírico). A parte conceitual, em que o valor cultural pode ser explorado, foi preterida tanto no material didático adotado quanto pela própria coordenadora do curso, que não explorou suficientemente a importância da autopromoção concretizada no gênero. 
Isso nos leva a questionar os limites do ensino do gênero textual com foco na descrição empírica. O aluno pode aprender as regras sem conhecer a razão da existência dessas regras, ou seja, a sua função social? O gênero textual faz sentido para o aluno se carregar um valor cultural que ele não compartilha (ou desconhece?)? Ele é capaz de realizar as regras linguisticamente se não possui proficiência suficiente? G é requisitado várias vezes na correção e na conferência a realizar os movimentos da introdução ("what is the purpose of this information?", "what is the gap?"), mas não o faz, optando inclusive pela eliminação de parágrafos. ${ }^{22}$

Todas essas questões são colocadas aqui para retomar uma discussão, encetada em outros trabalhos (FERREIRA; LANTOLF, 2008; FERREIRA, 2009), sobre o foco excessivo dos estudos genéricos na descrição empírica. $O$ valor cultural da autopromoção no artigo acadêmico constitui um exemplo de conhecimento conceitual (DANESI, 1995). Esse tipo de conhecimento se refere ao modo como uma comunidade concebe algo (um objeto, um conceito) e o manifesta linguisticamente na forma de expressóes idiomáticas e de metáforas conceituais, por exemplo (ANDREOU; GALANTOMOS, 2009). Como dito anteriormente, a autopromoção é expressa pela metáfora do nicho (estabelecer o nicho, preencher o nicho) assemelhando a competição acadêmica à competição natural. ${ }^{23}$ Esse conhecimento conceitual que sustenta e, portanto, explica a descrição empírica não é abordado nos manuais didáticos de redação acadêmica em inglês ou nos cursos. Essa mudança de foco nos estudos genéricos e no seu ensino poderia auxiliar no desenvolvimento de uma visão mais dialética e relacional (em que se busca o porquê das coisas, a essência que liga os fenômenos) do fenômeno gênero textual e, logo, da língua, favorecendo o desenvolvimento do pensamento teórico (o pensamento dialético para se compreender conceitos científicos) (VYGOTSKY, 1987).

A área de gêneros textuais necessita de maiores investigações sobre $o$ valor cultural que o gênero textual carrega e sobre a sua influência no aprendizado do gênero pelo aluno. No caso em análise, fica evidente que G não tinha consciência das implicações de suas escolhas retóricas, tanto no nível organizacional (a narração) quanto lexical (“initial”, “ideal”), que impediram que ele se promovesse no artigo, valorizando sua pesquisa.

22 Outra explicação para essa eliminação do parágrafo pode ser a insuficiência linguística do aluno para realizar os movimentos e passos pedidos.

${ }^{23}$ A metáfora aqui funcionaria até como um recurso de naturalização: competição na academia é natural, portanto, deve-se aceitar essa prática e suas consequências. 
O presente estudo de caso ilustra prováveis dificuldades de outros pósgraduandos com o letramento acadêmico em inglêse revela a premente necessidade de intervençôes pedagógicas sistemáticas para lidar com tal problema.

\section{Referências}

ANDREOU, G.; GALANTOMOS, I. Conceptual competence as a component of second language fluency. Journal of Psycholinguistic Research, Boston, v. 38, n. 6, p. 587-591, Dec. 2009.

ARAÚJO, A. D. Práticas discursivas em conclusōes de teses de doutorado. Linguagem em (Dis)curso, Tubarão, v. 6, n. 3, p. 447-462, set.-dez. 2006.

ASKEHAVE, I.; J. M. SWALES. Genre identification and communicative purpose: a problem and a possible solution. Applied Linguistics, v. 22, n. 2, p. 195-212, 2001.

BAKHTIN, M. M. Estética da criação verbal. São Paulo: Martins Fontes, 1992. $421 \mathrm{p}$.

BAZERMAN, C. Shaping written knowledge. Madison: The University of Wisconsin Press, 1988. 356 p.

BEATO-CANATO, A. P. M. O trabalho com línguas para fins específicos em uma perspectiva interacionista e discursiva. Revista Brasileira de Linguística Aplicada, Belo Horizonte, v. 11, n. 4, p. 853-870, 2011.

BERALDI, M.; FONTES, M. O uso da Teoria Sistêmico-Funcional em linguagem instrucional para produção de texto em inglês. The ESPecialist, São Paulo, v. 25, n. 1, p. 31-50, 2004.

BERKENKOTTER, C.; HUCKIN, T. N. Genre knowledge in disciplinary communication: cognition/culture/power. Hillsdale: Lawrence Earlbaum, 1995. $190 \mathrm{p}$.

BRANDT, D. Writing for a living: literacy and the knowledge of economy. Written Communication, v. 22, n. 2, p. 166-197, 2005.

CANAGARAJAH, S. 'Non-discursive' requirements in academic publishing, material resources of periphery scholars, and the politics of knowledge production. Written Communication, v. 13, n. 4, p. 435-472, 1996.

CANAGARAJAH, S. A geopolitics of academic writing. Pittsburgh: University of Pittsburgh Press, 2002. 332 p.

CASANAVE, C. P. Local interactions: constructing contexts for composing in a graduate sociology program. In: BELCHER, D.; BRAINE, G. (Ed.). Academic writing in a second language: essays on research and pedagogy. Norwood: Ablex, 1995. p. 83-110. 
CASTRO, R. A. L. Collaborative writing como dinâmica do curso de redação acadêmica. Claritas, São Paulo, v. 11, n. 2, p. 143-152, 2005.

CHARLES, M.; PECORARI, D.; HUSNTON, S. (Ed.). Academic writing: at the interface of corpus and discourse. London: Continuum, 2009. 303 p.

CHENG, A. Understanding learners and learning in ESP genre-based writing instruction. English for Specific Purposes, v. 25, n. 1, p. 76-89, 2006.

CONNOR, U. Intercultural rhetoric in the writing classroom. Ann Arbor: The University of Michigan Press, 2011. 136 p.

CONNOR, U., NAGELHOUT, E.; ROZYCKI, W. V. Contrastive rhetoric. Amsterdam: John Benjamins, 2008. 324 p.

DAMIÃO, S. M. Course design, action research and the use of computers: challenges in an ESP course. Revista Brasileira de Linguística Aplicada, Belo Horizonte, v. 11, n. 4, p. 913-934, 2011.

DANESI, M. Learning and teaching languages: the role of conceptual fluency. International Journal of Applied Linguistics v. 5, n. 1, p. 3-20, 1995.

DAVYDOV, V. V. The concept of theoretical generalization and problems of educational psychology. Studies in Soviet Thought, v. 36, p. 169-202, 1988a.

DAVYDOV, V. V. Problems of developmental teaching: the experience of theoretical and experimental psychology research. Soviet Education, v. 30, n. 8, p. 6-97, 1988b.

DAVYDOV, V. V. Problems of developmental teaching: the experience of theoretical and experimental psychological research. Soviet Education, v. 30, n. 9, p. 3-83, 1988c.

DAVYDOV, V. V. Problems of developmental teaching: the experience of theoretical and experimental psychological research. Soviet Education, v. 30, n. 10 , p. 3-77, $1988 \mathrm{~d}$.

DELLAGNELO, A. A influência do feedback do professor nas revisões de seus alunos. Linguagem e Ensino, Pelotas, v. 1, n. 2, p. 59-70, 1998.

DELLAGNELO, A.; TOMITCH, L. Preferências de alunos-escritores em L2 com relação a estratégias de revisão de texto. Linguagem e Ensino, Pelotas, v. 2, n. 1, p. 73-86, 1999.

DIAS, R. Concept maps powered by computer software: a strategy for enhancing reading comprehension in English for Specific Purposes. Revista Brasileira de Linguistica Aplicada, Belo Horizonte, v. 11, n. 4, p. 895-911, 2011.

DUSZAK, A. Cultures and styles of academic discourse. Berlin: Mouton de Gruyter, 1997. 362 p. 
FERREIRA, M. M. A concept-based approach to writing instruction: from the abstract concept to the concrete performance. 2005. $400 \mathrm{f}$. Thesis (Doctorate in Applied Linguistics) - The Penn State University, Pennsylvania, 2005.

FERREIRA, M. M. Uma aplicação da abordagem pedagógica 'Movimento do abstrato para o concreto' para o ensino de gênero textual. Revista Solta a Voz, v. 20, n. 1, p. 115-129, 2009.

FERREIRA, M. M. Desafios e implicações de um ensino com foco no desenvolvimento: a pedagogia de V. V. Davydov. In: LIBÂNEO, J. C.; SUANNO, M. V. R.; LIMONIA, S. V. (Ed.). Concepçôes e práticas de ensino num mundo em mudança. Goiânia: Editora da PUC-GO, 2011. p. 17-30.

FERREIRA, M. M.; LANTOLF, J. P. A concept-based approach to teaching: writing through genre analysis. In: LANTOLF, J. P.; POEHNER, M. P. (Ed.). Sociocultural theory and the teaching of second languages. London: Equinox, 2008. p. 285-320.

FERREIRA, M. M.; SANTOS, C. R. Plágio: concepções e práticas textuais de pós-graduandos. In: SIMPÓSIO INTERNACIONAL DE ESTUDOS DE GÊNEROS TEXTUAIS, 6., 2011, Natal. Anais... Disponível em: <http:// www.cchla.ufrn.br/visiget/>. Acesso em: 1 fev. 2012.

FIGUEIREDO, F. J. Q. Correção com os pares: os efeitos do processo da correção dialogada na aprendizagem da escrita em língua inglesa. 2001. $333 \mathrm{f}$. Tese (Doutorado) - Faculdade de Letras, Universidade Federal de Minas Gerais, 2001.

FIGUEIREDO, F. J. Q. Semeando a interação: a revisão dialógica de textos escritos em língua estrangeira. Goiânia: Editora da UFG, 2005.

FLOWERDEW, J.; PEACOCK, M. Issues in EAP. In: FLOWERDEW, J.; PEACOCK, M. (Ed.). Research perspectives on English for Academic Purposes. Cambridge, UK: Cambridge University Press, 2001. p. 8-24.

FREIRE, M. De reflexões sobre a prática profissional à elaboração de oficinas virtuais de redação. The ESPecialist, São Paulo, v. 21, n. 2, p. 147-180, 2000.

GARCIA, D. Os diários dialogados eletrônicos no ensino de língua estrangeira. Linguagem e Ensino, Pelotas, v. 7, n. 2, p. 17-36, 2004.

GEISLER, C. Academic literacy and the nature of expertise: reading, writing and knowing in academic philosophy. Hillsdale: Lawrence Earlbaum, 1994. 354 p. GIBBS, W. W. Lost science in the Third World. Scientific American, n. 273, p.76-83, Aug. 1995.

GUEDES, P. C. Da redação à produção textual: o ensino da escrita. São Paulo: Parábola, 2009. 343 p. 
GUIRALDELO, G. M.; DAMIÃO, S. M. A escrita em línguas estrangeira e materna em cursos de engenharias: relatos de experiências. The ESPecialist, São Paulo, v. 28, n. 1, p. 1-16, 2007.

HARWOOD, N. 'We do not seem to have a theory... The theory I present here attempts to fill this gap': Inclusive and exclusive pronouns in academic writing. Applied Linguistics, v. 26, n. 3, p. 343-375, 2005.

HYLAND, K. Directives: argument and engagement in academic writing. Applied Linguistics, v. 23, n. 2, p. 215-239, 2002.

HYLAND, K. Disciplinary interactions: metadiscourse in L2 postgraduate writing. Journal of Second Language Writing v. 13, n. 2, p. 133-151, 2004.

HYLAND, K. As can be seen: lexical bundles and disciplinary variation. English for Specific Purposes, v. 27, n. 1, p. 4-21, 2008.

IVANIC, R. Writing and identity: the discoursal construction of identity in academic writing. Amsterdam: John Benjamins, 1998. 373 p.

JOHNS, A. M. Text, role and context: developing academic literacies. Cambridge, UK: Cambridge University Press, 1997. 171 p.

JOHNS, A. M. An interdisciplinary, interinstitutional, learning communities program: student involvement and student success. In: LEKI, I. (Org.). Academic writing programs (case studies in TESOL Practice). Alexandria, VA: Teachers of English, 2001. p. 61-72.

JONES, C.; TURNER, J.; STREET, B. Students' writing in the university. Amsterdam: John Benjamins, 1999. $231 \mathrm{p}$.

JUZWIK, M. M. et al. Writing into $21^{\text {st }}$ century: an overview of research on writing, 1999 to 2004. Written Communication, v. 23, n. 4, p. 451-476, 2006. KHUWAILEH, A. O efeito do trabalho colaborativo interacional em sala de aula no tratamento dos erros em ensaios acadêmicos. The ESPecialist, São Paulo, v. 22, n. 2, p. 169-189, 2001.

KNORR-CETINA, K. D. The manufacture of knowledge. Oxford: Pergamon Press, 1981. 189 p.

LAIA, D. P. A escrita como prática pedagógica através das vozes dos alunos: suas crenças sobre o processo e a produção de textos escritos em LE (inglês). 2008. 184 f. Dissertação (Mestrado em Linguística Aplicada) - Instituto de Letras, Universidade de Brasília, Brasília, 2008.

LATOUR, B.; WOOLGAR, S. The laboratory life. Princeton: Princeton University Press, 1979. 294 p.

LILLIS, T. Student writing: access, regulation, desire. London: Routledge, 2001. $196 \mathrm{p}$. 
LILLIS, T.; CURRY, M. J. Academic Writing in a global context. London: Routledge, 2010. 203 p.

MACIAS-CHAPULA, C. A. O papel da infometria e da cienciometria e sua perspectiva nacional e internacional. Ciência da Informação, v. 27, n. 2, p. 134$140,1998$.

MAN, J. P. et al. Why do some countries publish more than others? An international comparison of research funding, English proficiency and publication output in highly ranked general medical journals. European Journal of Epidermiology, n. 19, p. 811-817, 2004.

MARTIN, J. R. Factual writing: exploring and challenging social reality. Oxford: Oxford University Press, 1989. 101 p.

MENEGHINI, R.; MUGNANI, R.; PACKER, A. L. International versus national oriented Brazilian scientific journals: a scientometric analysis based on Scielo and JCR-ISI databases. Scientometrics, v. 69, n. 3, p. 529-538, 2006.

PACKER, A. L.; MENEGHINI, R. Articles with authors affiliated to Brazilian institutions published from 1994 to 2003 with 100 or more citations. Anais da Academia Brasileira de Ciências, v. 78, n. 4, p. 841-853, 2006.

PECORARI, D. Plagiarism and international students: how the Englishspeaking university responds. In: BELCHER, D.; HIRVELA, A. (Ed.). Linking literacies: perspectives on L2 reading-writing connections. Ann Arbor: The University of Michigan Press, 2001. 351 p.

PECORARI, D. Academic writing and plagiarism. London: Continuum, 2003. $224 \mathrm{p}$.

PENNYCOOK, A. The cultural politics of English as an international language. London: Longman, 1994. 365 p.

ROJO, R. Letramentos múltiplos, escola e inclusão social. São Paulo: Parábola, 2009. $127 \mathrm{p}$.

SAMRAJ, B. Introductions in research articles: variations across disciplines. English for Specific Purposes, v. 21, p. 1-17, 2002.

SOLERA, D. S. Artigos cientificos da área de energia: um estudo sobre seção introdução e a interatividade. 2011. Artigo (Iniciação Científica) Departamento de Letras Modernas, Universidade de São Paulo, São Paulo, 2011. SOUZA, L. Ensino da produção escrita em lingua estrangeira (inglês) em um curso de línguas: influência da avaliação ou da concepção de escrita do professor? 2002. 125 f. Dissertação (Mestrado em Linguística Aplicada) - Instituto de Estudos da Linguagem, Unicamp, Campinas, 2002. 
STREET, B. Academic Literacies. In: JONES, C,; TURNER, J.; STREET, B. Students' writing in the university. Amsterdam: John Benjanins, 1998. p. 193227.

STREET, B. Literacy and development: ethnographic perspectives. London: Routledge, 2001. 228 p.

SWALES, J. M. Genre analysis. Cambridge, UK: Cambridge University Press, 1990. 260 p.

SWALES, J. M. Research genres. Cambridge, UK: Cambridge University Press, 2004. 314 p.

SWALES, J. M.; FEAK, C. B. English in today's research world. Ann Arbor: The University of Michigan Press, 2000. 293 p.

SWALES, J. M.; FEAK, C. B. Academic writing for graduate students. Ann Arbor: The University of Michigan Press, 2004. 331 p.

TARDY, C. M. Researching first and second language genre learning: a comparative review and a look ahead. Journal of Second Language Writing, v. 15, n. 1, p.79-101, 2006.

VASCONCELOS, S. M. R.; SORENSON, M. M.; LETA, J. Scientist-friendly policies for non-native English speaking authors; timely and welcome. Brazilian Journal of Medical and Biological Research, v. 40, n. 6, p. 743-747, 2007.

VYGOTSKY, L. S. The collected works of L. S. Vygotsky. New York: Plenum, 1987. v. 1.

WARSCHAUER, M. The changing global economy and the future of English teaching. Tesol Quaterly, v. 34, n. 3, p. 511-535, 2000.

WOOD, A. International scientific English. In: FLOWERDEW, J.; PEACOCK, M. (Ed.). Research perspectives on English for Academic Purposes. Cambridge, UK: Cambridge University Press, 2001. p. 71-83.

ZANINI, M. Uma visão panorâmica da teoria e da prática do ensino de língua materna. Acta Scientiarum, v. 21, n. 1, p. 79-88, 1999.

ZYGMANTAS, J. As implicaçōes do contexto de produção dos textos e sua organização textual na (re)construção de significados. The ESPecialist, São Paulo, v. 27 , n. 1, p. 63-81, 2006.

Recebido em 15/03/2012. Aprovado em 05/10/2012. 